\title{
A COMPARATIVE STUDY OF EXPLOSIVE STRENGTH AND SPEED VARIABLES OF SCHOOL LEVEL VOLLEYBALL PLAYERS OF URBAN AND RURAL AREA OF GANDHINAGAR
}

\section{$\underline{\text { Abstract }}$}

\section{Dr Nimeshkumar D. Chaudhari}

The purpose of the study was to compare the physical fitness variable of 15-19 years of urban and rural area of Gandhinagar district Gujarat in relation to their age. To fulfill the objective of the study 40 School level Volleyball player (20 each) players of Gandhinagar was selected. The age of the selected subjects ranged from 15 to 19 years. Only (Standing Board Jump and 50 yard dash tests) were used to measures the selected physical fitness variables of the players. The study was delimited to AAPHER youth fitness test. In order to analyze the data t-test was used to analyze the data and investigator observed the significant different between Rural and Urban School level Volleyball players of Gandhinagar district Gujarat.

Keywords: Urban, Rural, Volleyball, Male, Explosive strength and speed.

\section{$\underline{\text { Introduction }}$}

Physical fitness is ability to perform daily task with energy and alertness without under fatigue and still enjoy leisure time pursuits and to meet the unpredicted Emergencies. Physical fitness is defined as a set of ability to carry out physical ability. Regular physical exercise is an important part to remain fit and healthy. It keeps us active in the long run and we also feel better. Exercise can help you to remove some diseases like diabetes, prevention of cancer and heart problems (Rao, 2010)

Different people have a lot of view regarding physical fitness. Being a common Man to have a good physique is a symbol of physical fitness. According to doctor, the proper functioning of physiological systems is physical fitness. In fact, physical fitness is a simple term with a wide meaning. For a common man, Physical fitness means the capacity to do the routine work without any fatigue or exertion and after doing his work he has also energy to do some more work and the recovery is quicker. Physical fitness is more than the possession of strength and endurance. It means to maintain good physical fitness with the capacity to do ones everyday task to engage in recreational pursuits and to meet emergencies, when they arise. In fact, physical fitness is possessed by the individual with enthusiast with vigorous (Sharma, 2010)

The physical fitness was the sum of five motor abilities namely; speed, strength, endurance, flexibility and co-ordination abilities and their complex form like strength, endurance, maximum strength, explosive strength, maximum speed, and agility were the basic prerequisites of human motor action. Therefore, the sports performances depend to a greater extend on these abilities. (Ahmed, 2010)

In earlier time physical fitness has been define from different perspectives and estimated by using many methods. The conception of physical fitness based on military or athletic purpose which has 
survived centuries since the ancient Chinese and Athenian In 20th century, the definition of physical fitness has shifted slowly towards a work-or living-related conception. (Sharkey, 1991)

It forms an important part of physical education Programme in schools and colleges as coaches and physical education teachers follow different methods for selecting players for better performance is games and sports such as Volleyball.

\section{Objectives of the Study}

The proposed objectives of the present research were follows.

1. To measure the present level of Speed between Rural and Urban School level Volleyball players of Gandhinagar.

2. To measure the present level of Explosive Strength between Rural and Urban School level Volleyball players of Gandhinagar.

3. To compare the speed and explosive strength between Rural and Urban school level Volleyball players of Gandhinagar.

\section{Hypothesis of the study}

Having a view of objectives of the study, null hypothesis is framed for the present investigation.

\section{Delimitation of the study}

1. The present study was delimited on the following aspects such as:

2. Only 40 Male (20 Rural and 20 Urban) students were considered.

3. The age of the subjects were ranged from 15 to 19 years.

4. The physical fitness components i.e. - Explosive strength and speed considered for the present study.

\section{Method and Prouder}

Selection of the Subjects

1. The subjects were selected in following basis:

2. He should be male student.

3. He should attain the age of 15 years and not more than 19 years.

4. He should be study in Gandhinagar Gujarat.

5. Only rural and urban School level Volleyball players was consider for the study.

\section{Criterion Measures}

The criterion measures were used to collect the data in a deal and systematic way to record in a correct unit and style for each test item.

1. Explosive leg strength was measured by Standing Broad Jump test and scores were recorded in centimeters.

2. Speed was measured by 50 Yards Dash and time was recorded to the nearest $1 / 100$ of a second

\section{Statistical Techniques} with the help of digital stopwatch.

To find out the significance differences of selected physical fitness variables of male school level Rural and Urban volleyball male players independent samples t-test used as a statistical technique for the data analysis. The level of significance was set at 0.05 .

Results and Discussion

\section{Table 1:}

Comparison of Explosive Strength Component of Rural and Urban School level Volleyball male players of Gandhinagar in Standing Broad Jump. 


\section{Chaudhari / Page 1-4}

\begin{tabular}{|c|c|c|c|c|c|}
\hline \multirow[t]{2}{*}{ Variable } & \multicolumn{2}{|c|}{ Rural } & \multicolumn{2}{|c|}{ Urban } & 't'rati \\
\hline & $\begin{array}{c}\text { Mea } \\
\text { n }\end{array}$ & S.D & $\begin{array}{l}\text { Mea } \\
\text { n }\end{array}$ & S.D & 1.4 \\
\hline $\begin{array}{c}\text { Strength } \\
\text { (Standing Broad Jump) }\end{array}$ & 2.38 & $\begin{array}{c}0.2 \\
3\end{array}$ & 2.31 & 0.1 & \\
\hline
\end{tabular}

*Significant at .05 level

The mean score (2.38) of the explosive strength component of physical fitness of rural Volleyball players is high than the mean score (2.31) of Urban Volleyball players of Gandhinagar. However, the t-ratio is 1.4 , which is significant at 0.05 levels. High score better Explosive strength. It means that rural players of Volleyball players have better Explosive strength of physical fitness than the Urban Volleyball players of Gandhinagar.

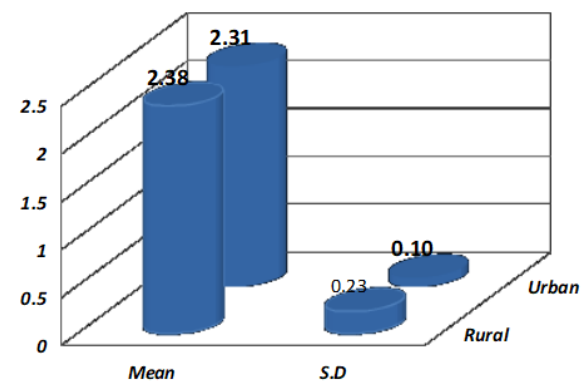

Fig 1: Comparison of Explosive Strength Component of Rural and Urban School level Volleyball players in Gandhinagar.

Table 2:

Comparison of Speed Component of Rural and Urban School level Volleyball male players of Gandhinagar in Standing Broad Jump.

\begin{tabular}{|c|c|c|c|c|c|}
\hline \multirow{2}{*}{ Variable } & \multicolumn{2}{|c|}{ Rural } & \multicolumn{2}{c|}{ Urban } & 't'rati \\
\cline { 2 - 5 } & Mean & S.D & Mean & S.D & \multirow{3}{*}{$3.88^{*}$} \\
\hline Speed & 7.79 & $\begin{array}{c}0.5 \\
\mathbf{5}\end{array}$ & 7.17 & 0.51 & \\
\hline
\end{tabular}

*Significant at .05 level

The mean score (7.79) of the speed component of physical fitness of rural Volleyball players is high than the mean score (7.17) of Urban Volleyball players of Gandhinagar. However, the' t'ratio is 3.88 which is significant at 0.05 level. High score better speed. It means that rural players of Volleyball players have better speed of physical fitness than the Urban Volleyball players of Gandhinagar.

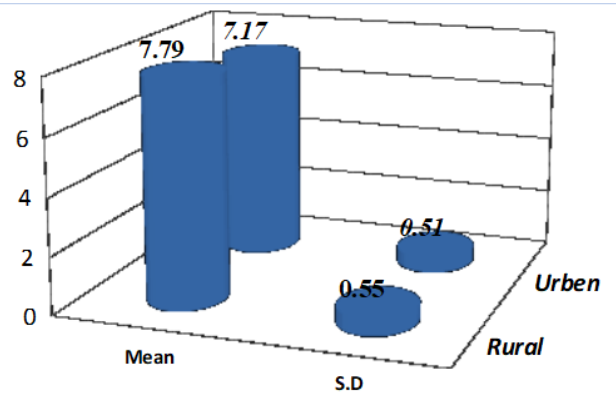


Fig 2: Comparison of Speed Component of Rural and Urban School level Volleyball male players of Gandhinagar.

\section{Conclusion}

On the basis of the analysis of data the Rural Volleyball players were having better mean values among speed and Explosive strength than Urban Volleyball players. Volleyball rural players performed better than the urban male players.

\section{References}

Ahmed, M. (2010). Comparison of selected physical fitness variables of 18 years old male cricket players. International Journal of Physical Fitness, 3, 50

Asgar, A. K., \& Mahbubur, R. (2003). Motor fitness of BKSP basketball players Journal of Sports Science, 2, 74

Bhowmick, S. (2001). Performance related fitness of BKSP boys participating in team games. Bangladesh Journal of Sports Science, 2, 73

Clarke and Clarke, Application of Measurements to Physical Education. New Jersy: The Prentice Hall Inc., 1998.

Dick, $\quad$ Frank W., Sports Training Principles, London: Henry Kimpton Publishers Limited, 1996.

Donald K. Mathew, "Measurement in Physical Education" (Philadelphia: W.B. Saunders company, 1978).

Hardyalsingh, "Sports training General theory and Method" (Patial: nataji subhash national institute of sports 1984).

Harold M. Barrow and Rose Marry Mc Gee, Practical Approach to Measurement in Physical Education. Englewood Cliffs, New Jersey: Prentice Hall, Inc., 1994.

Johnson, Barry L. and Jack K. Nelson, Practical Measurements for Evaluation in Physical Education. Delhi: The Surject Publications, 1998.

Rao, P. J. (2010). A comparative study on physical fitness among swimmers and Athletics between age group of 12 to 14 years. Asian Journal of Physical Education and Computer

Science in Sports, 2, 225-229.

Sharkey, B. J. (1991). New dimensions in aerobic fitness: current issues in exercise science. Champaign, IL:Human Kinetics.

Sharma, V. K. (2010). Health and Education. Saraswati house Pvt. Ltd., New Delhi, 1, 11.

Verma, Prakash, J. “A Text Book on Sports Statistics”, Gwalior: Venus Publication, India, 2000.

Uddin, R., Rahman, A., \& Md., S. (2015). Motor fitness of bksp male and female tennis players - a profile study International Journal of Physical Education, Health \& Sports Sciences, 4(1).

Uppal, A. K. (2001). Principles of sports training. Friends Publication, Delhi, India.

\section{Dr Nimeshkumar D. Chaudhari Assistant Professor Gujarat Vidyapith, Ahmedabad Faculty of Physical Education and Sports Science, AT. Sadra, Ta. Dist. Gandhinagar.(Gujarat)}

